\title{
Pituitary-hormone secretion by thyrotropinomas
}

\author{
Ferdinand Roelfsema $\cdot$ Simon Kok $\cdot$ Petra Kok $\cdot$ Alberto M. Pereira $\cdot$ \\ Nienke R. Biermasz · Jan W. Smit • Marijke Frolich • Daniel M. Keenan • \\ Johannes D. Veldhuis $\cdot$ Johannes A. Romijn
}

Published online: 3 December 2008

(C) The Author(s) 2008. This article is published with open access at Springerlink.com

\begin{abstract}
Hormone secretion by somatotropinomas, corticotropinomas and prolactinomas exhibits increased pulse frequency, basal and pulsatile secretion, accompanied by greater disorderliness. Increased concentrations of growth hormone (GH) or prolactin (PRL) are observed in about $30 \%$ of thyrotropinomas leading to acromegaly or disturbed sexual functions beyond thyrotropin (TSH)-induced hyperthyroidism. Regulation of non-TSH pituitary hormones in this context is not well understood. We there therefore evaluated TSH, GH and PRL secretion in 6 patients with upto-date analytical and mathematical tools by 24 -h blood sampling at 10-min intervals in a clinical research laboratory. The profiles were analyzed with a new deconvolution method, approximate entropy, cross-approximate entropy, cross-correlation and cosinor regression. TSH burst frequency and basal and pulsatile secretion were increased in patients compared with controls. TSH secretion patterns in patients were more irregular, but the diurnal rhythm was preserved at a higher mean with a $2.5 \mathrm{~h}$ phase delay. Although only one patient had clinical acromegaly, GH
\end{abstract}

F. Roelfsema $(\bowtie) \cdot$ S. Kok · P. Kok - A. M. Pereira

N. R. Biermasz - J. W. Smit - M. Frolich - J. A. Romijn

Department of Endocrinology and Metabolic Diseases, Leiden

University Medical Center, Albinusdreef 2, NL2333ZA Leiden,

The Netherlands

e-mail: f.roelfsema@lumc.nl

D. M. Keenan

Department of Statistics, University of Virginia, Charlottesville,

VA, USA

J. D. Veldhuis

Endocrine Research Unit, Mayo Medical and Graduate Schools, Clinical Translational Research Center, Mayo Clinic, Rochester, MN, USA secretion and IGF-I levels were increased in two other patients and all three had a significant cross-correlation between the GH and TSH. PRL secretion was increased in one patient, but all patients had a significant cross-correlation with TSH and showed decreased PRL regularity. CrossApEn synchrony between TSH and GH did not differ between patients and controls, but TSH and PRL synchrony was reduced in patients. We conclude that TSH secretion by thyrotropinomas shares many characteristics of other pituitary hormone-secreting adenomas. In addition, abnormalities in GH and PRL secretion exist ranging from decreased (joint) regularity to overt hypersecretion, although not always clinically obvious, suggesting tumoral transformation of thyrotrope lineage cells.

Keywords Thyrotropin - TSH · Growth hormone · Prolactin - Thyrotropinoma - Deconvolution .

Approximate entropy · Diurnal rhythm · Phase shift .

Hormone secretion

\section{Introduction}

The major regulators of thyrotropin (TSH) secretion are thyrotropin-releasing hormone (TRH), the inhibitory neurotransmitters dopamine and somatostatin, and negative feed back by thyroid hormones, thyroxine and triiodothyronine [1]. The interplay among these regulators in time dictates the TSH secretion pattern, which is characterized by a diurnal variation of serum TSH concentrations with superimposed (small) bursts. The 24-h secretion profile of TSH has been well described in various pathophysiological conditions, including hyperthyroidism, hypothyroidism, obesity, fasting and in non-thyroidal illness, but not in detail in hyperthyroidism caused by a pituitary 
TSH-secreting adenomas [2-6]. TSH-secreting adenomas are relatively rare pituitary tumors (less than $1 \%$ of all pituitary adenomas), and are usually diagnosed when the TSH level is inappropriately elevated in a patient with raised serum thyroxine levels, combined with the presence of a pituitary (micro) adenoma [7]. In other hormonesecreting pituitary adenomas, e.g. Cushing's disease and prolactinomas, hormone secretion is marked by diminished or absent diurnal amplitude (one-half the difference between maximal and minimal concentrations), increased basal (i.e. non-pulsatile) secretion, elevated pulse frequency and reduced secretory regularity [8-10].

By analogy with results obtained in other hormonesecreting pituitary adenomas, we hypothesized that patients with thyrotropinomas would display a blunted diurnal secretion pattern, heightened basal and pulsatile TSH release, increased pulse frequency and attenuated regularity. Moreover, TSH adenomas may co-secrete other pituitary hormones, most frequently growth hormone and in decreasing order prolactin and gonadotropins, as well as uncombined $\alpha$-subunit [7]. To examine the mechanistic secretory similarities between TSH and co-secreted hormones, we quantitated correlations between hormone concentration time series (TSH, GH, prolactin and $\alpha$-subunit) using selected model-free tools. Finally, many patients with thyrotropinomas are currently treated with slow-release somatostatin analog formulations. Therefore we also explored the changes in fasting hormone levels in patients treated with long-acting somatostatin analogs. To this end serum hormone concentration profiles of six patients with thyrotropinomas were compared with those of 18 healthy controls that were investigated in a strictly comparable way.

\section{Patients and methods}

Six patients $(4 \mathrm{~m} / 2 \mathrm{f})$ with central hyperthyroidism caused by a TSH-secreting adenoma and 18 healthy non-obese (BMI $\left.18-25 \mathrm{~kg} / \mathrm{m}^{2}\right)$ control subjects of similar sex $(12 \mathrm{~m} / 6 \mathrm{f})$ and age distribution were enrolled in this study, after giving written acknowledgment of informed consent for participation. All premenopausal controls were required to have a regular menstrual cycle and not use oral contraceptives. Female subjects were studied in the early follicular phase of their menstrual cycle. Chronic disease, depression (present or in history), smoking, recent transmeridional flights, night shift work, weight change ( $>3 \mathrm{~kg}$ in 3 months), and use of medication (except for the patients) were exclusion criteria. All control subjects had an unremarkable medical history, and no abnormalities were found during physical examination, standard laboratory hematology, and blood chemistry and urine tests.
Clinical protocol

The protocol was approved by the Medical Ethics Committee of the Leiden University Medical Center (Leiden, The Netherlands). Subjects were admitted to the Clinical Research Unit of the Department of Internal Medicine. A cannula for blood sampling was inserted into an antecubital vein. The cannula was attached to a three-way stopcock and kept patent by a continuous saline infusion. Blood samples were taken at 10-min intervals for determination of plasma TSH, GH, prolactin and $\alpha$-subunit concentrations. Subjects remained recumbent, except for bathroom visits. No daytime naps were allowed. Meals were served according to a fixed time schedule. Lights were switched off at $2300 \mathrm{~h}$. Vital signs were recorded at regular time intervals, and great care was taken not to disturb patients while sampling blood during their sleep (no electroencephalography sleep recording was performed).

\section{Assays}

Samples were centrifuged at 4000 rotations $/ \mathrm{min}$ at $4{ }^{\circ} \mathrm{C}$ for $20 \mathrm{~min}$, within $60 \mathrm{~min}$ of sampling. Subsequently, plasma was divided into separate aliquots and frozen at $-80^{\circ} \mathrm{C}$ until assays were performed. Samples of each subject were determined in the same assay run. Plasma TSH concentrations were measured with a time-resolved immunofluorometric assay (Wallac, Turku, Finland), and its standard was calibrated against the World Health Organization second standard International Reference Preparation (80/558) hTSH for immunoassays. The limit of detection was $0.05 \mathrm{mU} / \mathrm{liter}$, and the interassay coefficient of variation was less then $5 \%$. Free $\mathrm{T}_{4}\left(\mathrm{fT}_{4}\right)$ was estimated using an automated system (Elecsys 2010, Roche Diagnostics Nederland BV, Almere, Netherlands). Triiodothyronine was measured with Abbott Axsym (Abbott Park, IL).

GH was measured with a sensitive time-resolved fluoroimmunoassay (Wallac Oy, Turku, Finland). The assay is specific for the $22 \mathrm{kDa}$ GH. The standard was biosynthetic recombinant human GH (Genotropin, Pharmacia \& Upjohn, Uppsala, Sweden), and was calibrated against the WHO First International Reference Preparation 80/505 (to convert $\mu \mathrm{g} / \mathrm{l}$ to $\mathrm{mU} / \mathrm{l}$ multiply by 2.6 ). The limit of detection of this assay (defined as the value $2 \mathrm{SD}$ above the mean value of the zero standards) was $0.01 \mathrm{mU} / 1(0.0038 \mathrm{ng} / \mathrm{ml})$. The intraassay coefficient of variation varied between 1.6 and $8.4 \%$ in the range from 0.01 to $18 \mu \mathrm{g} / \mathrm{l}$ and interassay coefficient of variation was $2.0-9.0 \%$ in the same range.

Total IGF-I was determined by RIA (Incstar, Stillwater, $\mathrm{MN}$ ) after extraction and purification on ODS-silica columns. The intraassay coefficient of variation was less than 11\%. The detection limit was $1.5 \mathrm{nmol} / \mathrm{l}$. Age-related normal data were determined in the same laboratory. 
Plasma PRL concentration was measured with a sensitive time-resolved fluoroimmunoassay with a detection limit of $0.04 \mu \mathrm{g} / \mathrm{l}$ (Delfia, Wallac Oy, Turku, Finland). The intra-assay coefficient of variation varied from 2.0 to $3.3 \%$ and inter-assay coefficient of variation is $3.4-6.2 \%$, in the concentration range from 3.0 to $80 \mu \mathrm{g} / \mathrm{l}$.

The $\alpha$-subunits were measured by an immunoradiometric assay (Immunotech, Marseille, France). The assay is calibrated with WHO International Reference Preparation $75 / 569$, and $1 \mathrm{mU}$ is equivalent to $1 \mu \mathrm{g}$. The intra-assay coefficient of variation was $6.8 \%$ and the inter-assay coefficient of variation $9.1 \%$ in the concentration range observed here.

\section{Calculations and statistics}

\section{Deconvolution analysis}

Each hormone concentration time series was analyzed using a recently validated deconvolution method [11]. The automated Matlab program first detrends the data and normalizes concentrations to the unit interval $[0,1]$. Second, successive potential pulse-time sets, each containing one fewer burst, are created by a smoothing process (a nonlinear adaptation of the heat-diffusion equation). Third, a maximum-likelihood expectation (MLE) deconvolution method estimates all secretion and elimination rates simultaneously for each candidate pulse-time set. The deconvolution model specifies basal secretion $\left(\beta_{0}\right)$, two half-lives $\left(\alpha_{1}, \alpha_{2}\right)$, an accumulation process and weak interpulse length dependency for secretory-burst mass $\left(\eta_{0}\right.$, $\left.\eta_{1}\right)$, random effects on burst mass $\left(\sigma_{\mathrm{A}}\right)$, procedural and measurement error $\left(\sigma_{\varepsilon}\right)$, and a 3-parameter secretory-burst waveform $\left(\beta_{1}, \beta_{2}, \beta_{3}\right)$. Model selection is performed to distinguish among the candidate pulse-time sets using the Akaike information criterion [12]. Observed interpulse intervals are described by a 2-parameter Weibull process (more general form of a Poisson renewal process). The parameters (and units) are frequency (number of bursts per unit time, lambda of Weibull distribution), regularity of interpulse intervals (unitless gamma of Weibull), slow halflife (min), basal and pulsatile secretion rates (concentration per unit time), mass secreted per burst (concentration), and waveform mode (time delay to maximal secretion after burst onset, $\min$ ) [11].

\section{Approximate entropy (ApEn)}

Approximate entropy, ApEn, is a scale-and model-independent univariate regularity statistic used to quantitate the orderliness (subpattern consistency) of serial stationary measurements [13, 14]. Mathematical models and feedback experiments establish that pattern orderliness monitors feedback and/or feedforward interactions within an interlinked axis with high sensitivity and specificity, both $>90 \%$ [15]. Reduced pattern regularity typifies hormone secretion in puberty and aging, during diminished negative feedback or fixed exogenous stimulation, and by autonomous neuroendocrine tumors $[16,17]$. Data are presented as normalized ApEn ratios, defined by the mean ratio of absolute ApEn to that of 1000 randomly shuffled versions of the same series. ApEn ratios close to 1.0 express high irregularity (mean randomness) of pulsatile hormone patterns.

Cross-Approximate Entropy (X-ApEn) is a scale- and model-independent two-variable regularity statistic used to quantitate the relative pattern synchrony of coupled time series [18, 19]. Clinical experiments establish that changes in two-hormone synchrony monitor feedback and/or feedforward adaptations within an interlinked axis with high sensitivity and specificity [15]. To normalize comparisons among subjects, $\mathrm{X}$-ApEn is computed on the paired original time series (observed X-ApEn) and then recalculated 1000 times after each series in a pair is shuffled randomly [rearranged in order or sequence without replacement or loss (random X-ApEn). Repetition of the permutation procedure allows calculation of the maximum, mean, and $\mathrm{SD}$ of random X-ApEn for a given series length and assay pair. A normalized distributional measure is then the number of SDS ( $\mathrm{z}$ scores) separating observed from the maximum or mean random X-ApEn. Higher absolute $z$ scores denote more synchronous patterns. Lower X-ApEn ratios and higher absolute $\mathrm{z}$ scores denote greater pattern synchrony between (coordinate control of) the interlinked signals. Reduced regularity of hormone secretion typifies puberty, aging, diminished negative feedback due to targetgland failure, fixed exogenous stimulation, and autonomous neuroendocrine tumors $[20,21]$.

\section{Diurnal rhythmicity}

Nyctohemeral variation of TSH concentrations was determined by a nonlinear unweighted least-squares cosine regression, as reported earlier [22]. Ninety-five percent statistical confidence intervals were determined for the 24-h cosine amplitude (50\% of the zenith-nadir difference), mesor (rhythmic mean) and acrophase (clock time of maximal value).

\section{Statistics}

Data are presented as mean \pm SEM, unless otherwise specified. Means of TSH concentration and secretion parameters of both groups were compared using two-tailed independent Student's $t$-test after logarithmic transformation or with the Kolmogorov-Smirnov two-sample test. 
Conventional cross-correlations between hormone concentration series were calculated after prewhitening of the series by first differencing in order to prevent spurious correlations. Statistical calculations were performed with Systat software, version 11 (Systat Inc, San Jose, CA). Significance level was set at 0.05 .

\section{Clinical presentation of the patients}

Patient 1 was studied when he was 73 years old. His medical history revealed that he underwent thyroid surgery at the age of $53 \mathrm{yr}$ because of presumed hyperthyroidism. After surgery he developed visual complaints and headaches and he was diagnosed with a large pituitary adenoma. He underwent pituitary surgery and because of incomplete resection pituitary irradiation as well. He was treated with thyroxine, testosterone supplements and cortisone acetate. For the pituitary tumor residue he received first bromocriptine, and later when immunostaining revealed $\beta$-TSH, short-acting octreotide, $100 \mu \mathrm{g}$ t.i.d. The 24-h blood sampling study was performed after withholding octreotide for 4 weeks. He is currently treated with octreotide-LAR, hydrocortisone, thyroxine and testosterone replacement.

Patient 2, aged 44 years was referred of acromegaly and central hyperthyroidism. After detailed clinical studies and pretreatment with sc octreotide (100 $\mu \mathrm{g}$ t.i.d.) he underwent transsphenoidal adenomectomy leading to biochemical cure of the central hyperthyroidism, but insufficient control of $\mathrm{GH}$ secretion. He is currently treated with octreotide only.

Patient 3, aged 38 years was evaluated at a teaching hospital because of weight loss and nervous symptoms. She was hyperthyroid, but TSH levels were not suppressed and MRI of the pituitary gland revealed a macroadenoma. For detailed endocrine studies she was referred to the Leiden University Medical Center. Subsequently, she was treated with octreotide LAR, with a favorable clinical response. After one year of treatment the 24-h blood sampling study was repeated.

Patient 4, aged 26 years was referred because of long-standing nervousness, palpitations and excessive perspiration. He appeared to be hyperthyroid with nonsuppressed TSH levels. Further studies revealed a pituitary adenoma and detailed biochemical studies, including a 24h blood sampling were carried out. He was treated with octreotide LAR with good clinical response. After 3 years he underwent a repeat 24-h blood sampling study.

Patient 5, aged 61 years was referred because of central hyperthyroidism and a pituitary microadenoma. Detailed biochemical studies were carried out, including a 24-h blood sampling. The patient, however, refused treatment. During infrequent follow-up visits for the last 12 years his clinical condition and TSH and thyroid hormone levels remained unchanged.

Patient 6, aged 60 years was medically treated in 1998 for hyperthyroidism in another hospital for one year. In 2006 she was reevaluated because of persisting hyperthyroid complaints, which were confirmed by biochemical analyses. In addition, the TSH levels were non-suppressed and the MRI of the pituitary gland revealed a macroadenoma. After the endocrine studies in our facility, treatment with octreotide LAR $20 \mathrm{mg}$ was started. However, although TSH concentration decreased, T4 levels remained elevated, so that after 3 months the octreotide dose was increased to $30 \mathrm{mg} / 4$ weeks without a clinical satisfactory response. Subsequently, it was found that she had a toxic nodular hyperthyroidism as well, for which was recently treated with strumazol and radioactive iodine (613 Mbq). Because of atrial fibrillation she was put on anticoagulant therapy and octreotide LAR was withheld.

Clinical and biochemical details of the patients are displayed in Table 1. One patient had severe acromegaly, and two other patients had slightly elevated IGF-I concentrations.

\section{Results}

Results of the i.v. $200 \mu \mathrm{g}$ TRH test are shown in Fig. 1. Without exception the TSH increase was subnormal,

Table 1 Clinical characteristics of the patients

\begin{tabular}{|c|c|c|c|c|c|c|c|c|c|}
\hline Patient & Gender & Age & $\begin{array}{l}\mathrm{fT}_{4} \\
(\mathrm{nmol} / \mathrm{l})\end{array}$ & $\begin{array}{l}\mathrm{T}_{3} \\
(\mathrm{nmol} / \mathrm{l})\end{array}$ & $\begin{array}{l}\mathrm{TSH} \\
(\mathrm{mU} / \mathrm{l})\end{array}$ & $\begin{array}{l}\alpha \text {-Subunit/TSH } \\
\text { molar ratio }\end{array}$ & $\begin{array}{l}\text { Thyroid } \\
\text { size }\end{array}$ & Pituitary MRI & $\begin{array}{l}\text { Immunostaining } \\
\text { adenoma }\end{array}$ \\
\hline 1 & Male & 73 & 31 & n.d. & 4.30 & 3.99 & Enlarged & Macroadenoma & TSH + \\
\hline 2 & Male & 44 & 47 & 4.1 & 3.01 & 7.80 & Enlarged & Macroadenoma & $\mathrm{GH} / \mathrm{TSH}+/+$ \\
\hline 3 & Female & 38 & 36 & 3.2 & 1.40 & 1.30 & Enlarged & Macroadenoma & n.a \\
\hline 4 & Male & 26 & 30 & 4.2 & 3.35 & 0.93 & Enlarged & Macroadenoma & n.a \\
\hline 5 & Male & 61 & 34 & 3.3 & 5.84 & 0.62 & Enlarged & Microadenoma & n.a \\
\hline 6 & Female & 60 & 38 & 3.2 & 1.01 & 14.1 & Enlarged & Macroadenoma & n.a \\
\hline
\end{tabular}

Normal range (median) for fT4: 10-24 (16.0) nmol/l, normal range for T3 1.1-3.0 (2.1) nmol/l, normal range for TSH 0.72-2.99 (1.25) mU/l. n.d. not determined, n.a. not applicable 

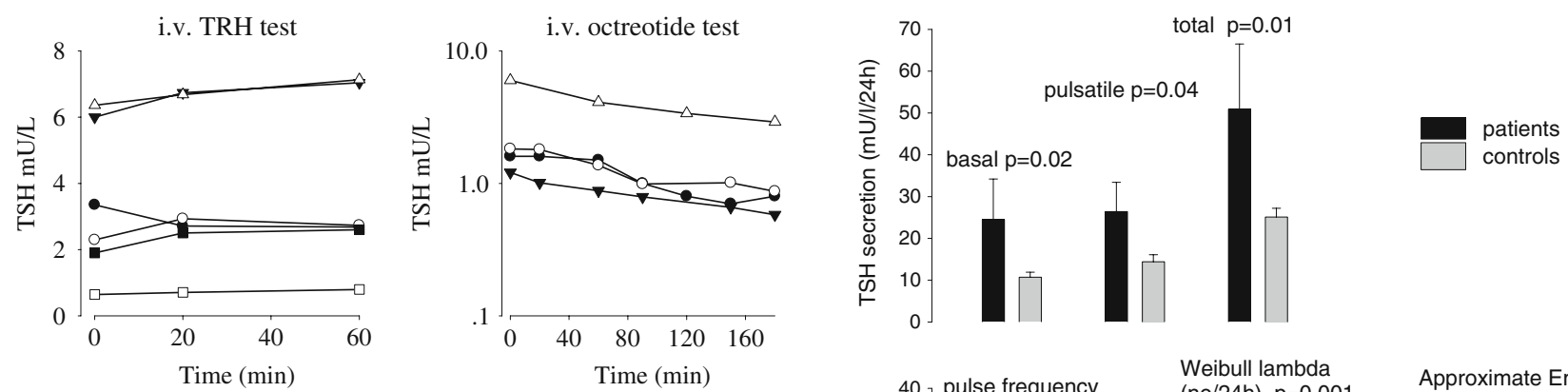

Fig. 1 Serum TSH response to $100 \mu \mathrm{g}$ TRH. Note the subnormal response in all patients (Left panel). Effect of intravenous octreotide injection on TSH concentrations. Note the logarithmic scale of the abscissa (Right panel)

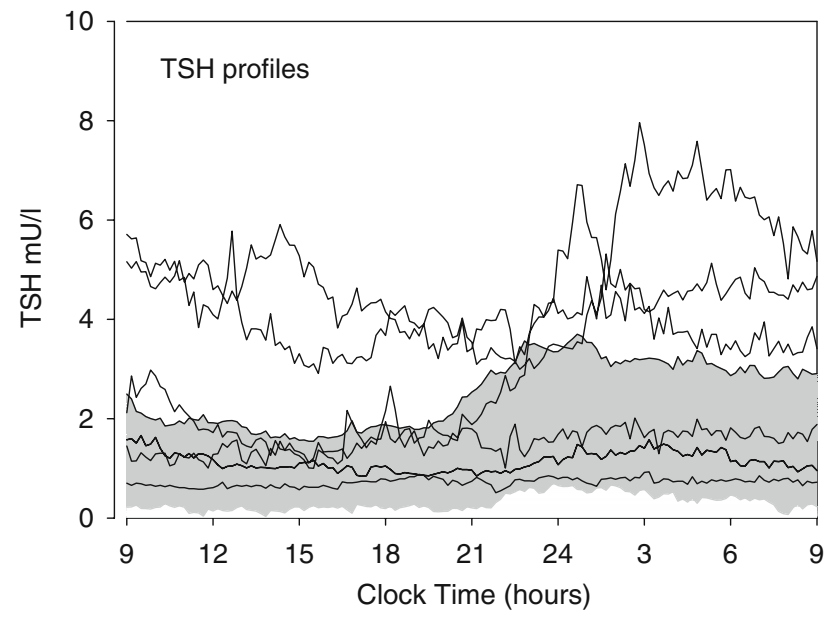

Fig. 2 Serum TSH concentration profiles of 6 patients with a thyrotropinoma. The shaded zone represents the $95 \%$ confidence interval of 18 healthy matched control subjects

ranging from 0 to $37 \%$, with a mean of $15 \%$ (normal values exceeding $100 \%)$. An octreotide test $(50 \mu \mathrm{g}$ i.v.) was performed in 4 patients and the results are shown in Fig. 1. Acute inhibition of serum TSH concentration was remarkably similar among patients with a mean of $56 \%$, ranging from 52 to $65 \%$.

Serum TSH concentration profiles of the 6 investigated patients are shown in Fig. 2 with the 95\% confidence interval for TSH profiles of non-obese controls. Results of the deconvolution analysis and of approximate entropy of the TSH concentration profiles are shown in Fig. 3. TSH secretion in thyrotropinoma patients was characterized by increased hormone burst frequency. Furthermore, basal and pulsatile TSH secretion was increased in patients, but the secretion-burst shape (waveform) was unchanged, as indicated by the mode. TSH secretory regularity of the subordinate patterns in patients was markedly decreased (increased ApEn ratio). Regularity of the interburst intervals however, was unchanged as demonstrated by the Weibull gamma results.

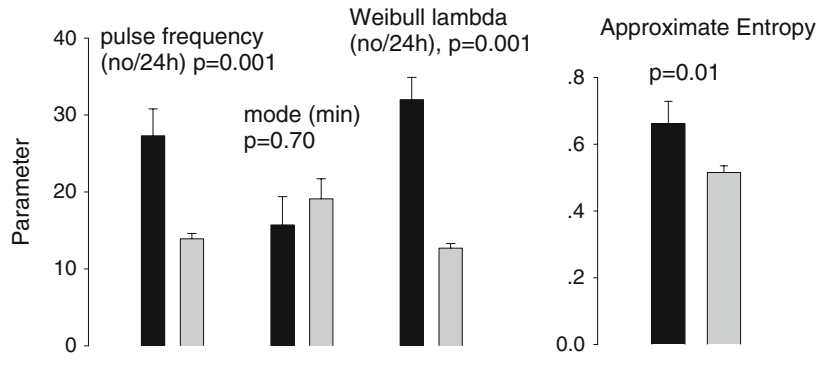

Fig. 3 Results of the deconvolution analysis and approximate entropy calculation of the TSH profiles of 6 thyrotropinoma patients and 18 healthy controls. Data are mean \pm SEM

The estimated first component of the TSH half-life did not differ in patients and controls $(24.5 \pm 2.5$ vs. $22.2 \pm 2.2 \mathrm{~min}$ ), but the slow component was shorter in patients ( $87.9 \pm 10.7$ vs. $108 \pm 4.3 \mathrm{~min}, P=0.048)$. This could denote reduced sialylation of tumoral TSH.

With the exception of one patient, GH secretion as also analyzed. The results are summarized in Table 2 and the GH concentration profiles are displayed in Fig. 4. Serum IGF-I concentrations and standard deviation scores were increased in patients $1-3$, of whom only patient 2 had clinically active disease. However, patients 1 and 3 had (slightly) increased GH secretion, with respect to age and both had a definitely abnormal GH secretion profile, compared with the other two patients and examples of healthy controls (Fig. 4). Approximate entropy for $\mathrm{GH}$ secretion was only increased in the patient with active acromegaly.

Serum prolactin concentration profiles are displayed in Fig. 5. One patient (\#3) had increased levels throughout the 24-h cycle, and two others had raised levels during the daytime. In contrast, the irradiated patient had subnormal levels. The regularity of PRL patterns in patients was diminished compared with controls, as defined by higher ApEn ratios in patients $(0.788 \pm 0.074$, mean \pm SD) than controls $(0.461 \pm 0.131, P<0.001)$.

We also investigated cross-correlations between 24-h TSH concentrations and each of GH, $\alpha$-subunit and PRL. Profiles of the serum concentrations of GH and TSH in two patients were rather similar, as illustrated in Fig. 6. The cross-correlation outcomes are shown in Table 3. Three patients had a highly significant correlation between serum 
Table 2 Growth hormone secretion in thyrotropinoma

\begin{tabular}{|c|c|c|c|c|c|c|c|}
\hline Patient & Age (years) & Sex & Fasting GH (mU/l) & $\begin{array}{l}\text { GH secretion } \\
(\mathrm{mU} / 1 / 24 \mathrm{~h})\end{array}$ & IGF-I $(\mu \mathrm{g} / \mathrm{l})$ & IGF-I SDS & ApEn ratio \\
\hline 1 & 73 & Male & 2.0 & 169 & 228 & 3.00 & 0.483 \\
\hline 2 & 44 & Male & 142 & 17070 & 550 & 10.4 & 0.787 \\
\hline 3 & 38 & Female & 1.90 & 205 & 274 & 2.23 & 0.433 \\
\hline 4 & 26 & Male & 0.11 & 174 & 144 & 0.02 & 0.310 \\
\hline 5 & 61 & Male & 0.20 & n.d. & 182 & 1.80 & n.d. \\
\hline 6 & 60 & Female & 2.50 & 81 & 135 & 1.16 & 0.480 \\
\hline Controls & $30-68(49)$ & Male & $0.02-1.10(0.18)$ & $116-200(45)$ & $75-185$ (107) & - & $0.181-0.558(0.330)$ \\
\hline Controls & $21-70(37)$ & Female & $0.06-2.80(0.56)$ & $57-247(123)$ & $87-234(143)$ & - & $0.260-0.514(0.380)$ \\
\hline
\end{tabular}

GH secretion was calculated with deconvolution of the $24 \mathrm{~h}$ serum GH concentration profiles. Control values were obtained from 26 male and 22 female healthy subjects, who were investigated in a similar way. Data for controls are shown as the range and median. $n . d$. not determined, SDS standard deviation score
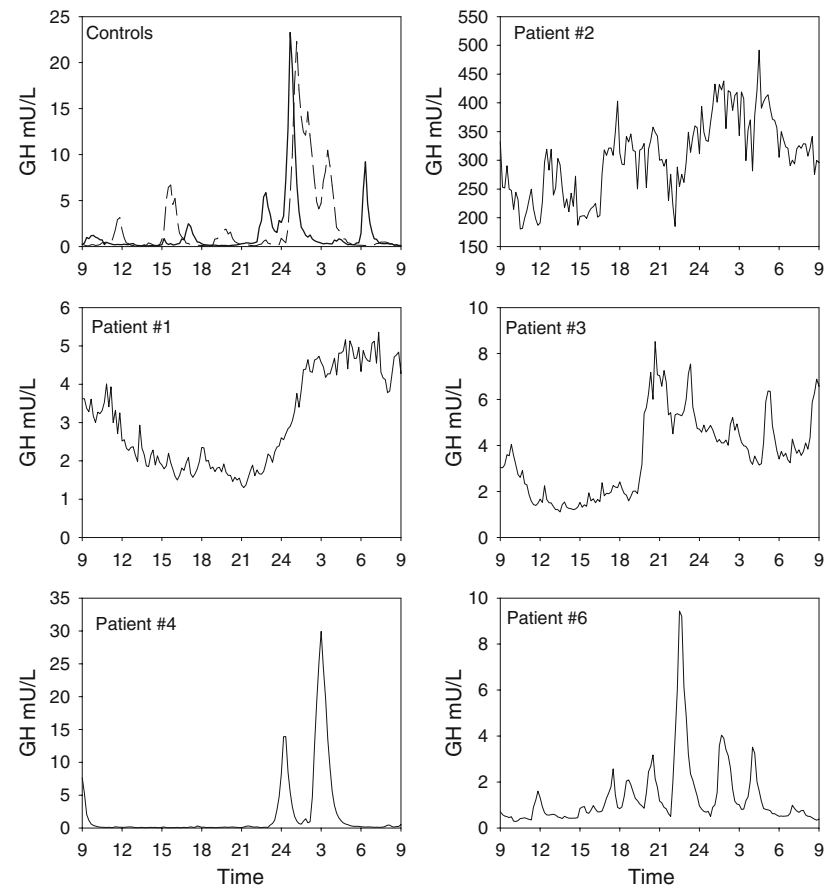

Fig. 4 Serum GH concentration profiles of 5 patients with a thyrotropinoma and 2 healthy representative controls (left upper panel, continuous line male subject, dashed line female subject). Note the difference in scales of the abscissa. The GH secretion patterns of patients \#1-3 are clearly abnormal, while that of patient \#6 only shows an increased basal (interpulse) level

TSH and GH concentrations. In contrast, in healthy controls no correlation between these two hormones could be demonstrated. In two of 5 patients a significant correlation could be demonstrated between serum TSH and $\alpha$-subunits concentrations, where an almost $100 \%$ concordance was expected when $\alpha$-subunits are truly co-secreted with TSH. Unfortunately, we have no comparable data in controls subjects. The cross-correlation between TSH and prolactin was significant in all patients. However, two-thirds of

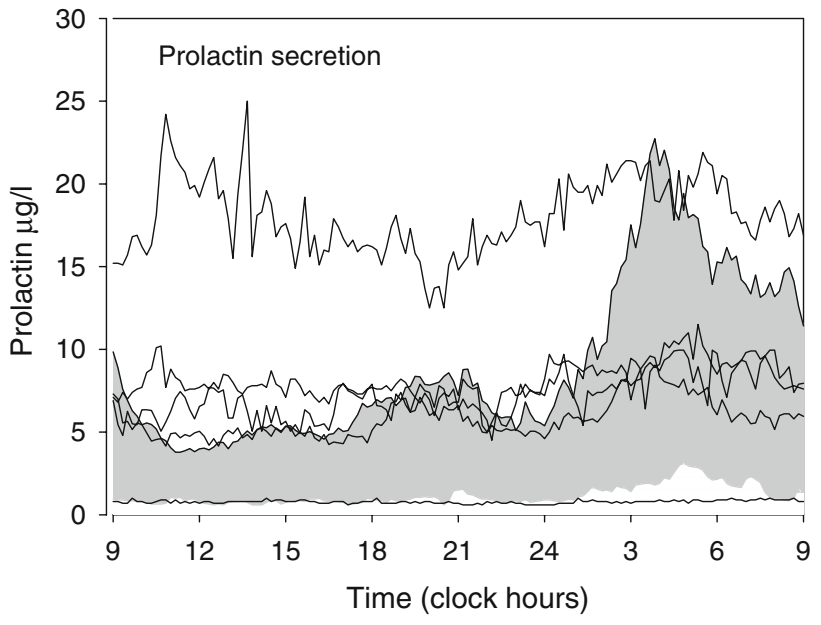

Fig. 5 Serum prolactin concentration profiles of 5 patients with a thyrotropinoma. The shaded area represents the 95\% confidence interval obtained from 18 matched healthy controls. The lowest profile was obtained in the irradiated patient
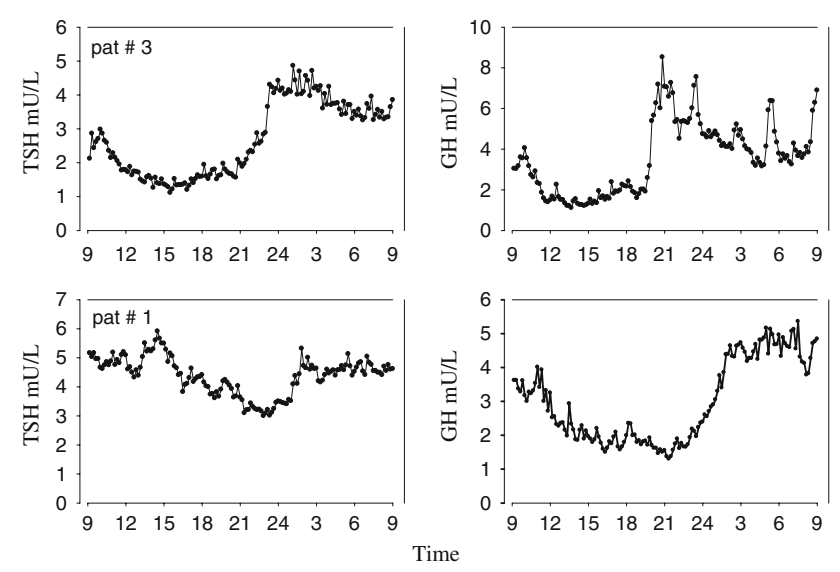

Fig. 6 TSH and GH profiles of 2 patients with a thyrotropinoma. Note the similarity of the patterns of both hormones 
Table 3 Cross-correlations between TSH, GH and $\alpha$-subunits in thyrotropinoma

\begin{tabular}{llll}
\hline Patient & TSH/GH & TSH/ $\alpha$-subunits & TSH/prolactin \\
\hline 1 & $0.337 \pm 0.083$ & n.s. & $0.350 \pm 0.083$ \\
2 & $0.345 \pm 0.084$ & $0.427 \pm 0.084$ & $0.428 \pm 0.083$ \\
3 & $0.279 \pm 0.084$ & n.s. & $0.190 \pm 0.085$ \\
4 & n.s. & $0.320 \pm 0.121$ & $0.385 \pm 0.083$ \\
6 & n.s. & n.s. & $0.405 \pm 0.083$ \\
\hline
\end{tabular}

Cross-correlations were calculated after removing autocorrelations by first differencing. n.s. non-significant

healthy controls also showed a significant correlation between these two hormones, with a median correlation coefficient of 0.300 , range $0.176-0.360$.

Cross-ApEn ratios for TSH and GH were similar in patients and controls $(0.716 \pm 0.085$ in patients vs. $0.678 \pm 0.018$ in controls), but cross-ApEn ratios for TSH and prolactin were increased in patients $(0.774 \pm 0.041$ vs. $0.547 \pm 0.022, P=0.001$ ), denoting significant loss of pattern synchrony.

All patients had significant diurnal TSH and PRL rhythms. For TSH the acrophase of the rhythm was shifted (timedelayed) from 2.83 to $5.58 \mathrm{~h}(P=0.02)$ and for PRL from 4.36 to $6.20 \mathrm{~h}(P=0.07)$. For TSH amplitudes were $0.83 \pm 0.29 \mathrm{mU} / \mathrm{l}$ in patients and $0.54 \pm 0.25 \mathrm{mU} / \mathrm{l}$ in controls (mean $\pm \mathrm{SD}, P=0.09$ ), and for PRL $1.43 \pm 0.44 \mu \mathrm{g} / 1$ and $0.97 \pm 0.60 \mu \mathrm{g} / \mathrm{l}$, respectively $(P=0.09)$.

\section{Effect of octreotide treatment}

Five of the six patients received octreotide as medical treatment, 4 as octreotide LAR. One patient (\#5) refused medication. One other patient (\#1) was treated preoperatively with octreotide (200 $\mu \mathrm{g}$ t.i.d.) for 3 months. Subsequently, he underwent transsphenoidal surgery, but had still (slightly) increased GH and IGF-I concentrations afterwards although TSH and thyroid hormone concentrations became and remained normal. This patient was treated with octreotide for the persisting GH excess. Finally, patient \#6 had also a toxic nodular goiter, for which she was treated with radioactive iodine and suppressive thyroid medication after initial failure of normalization of thyroid hormone concentrations associated with (moderate) decrease of already low TSH levels. The effect of octreotide on fasting morning thyroxine, TSH, GH, IGF-I, prolactin and $\alpha$-subunit concentrations is shown in Fig. 7. Free thyroxine concentrations normalized in all but one with a parallel reduction of TSH and also of IGF-I, GH and prolactin concentrations. The size of the adenoma on MRI decreased slightly in patients \#3 and 4, but remained unchanged in patients \#2 and 6.
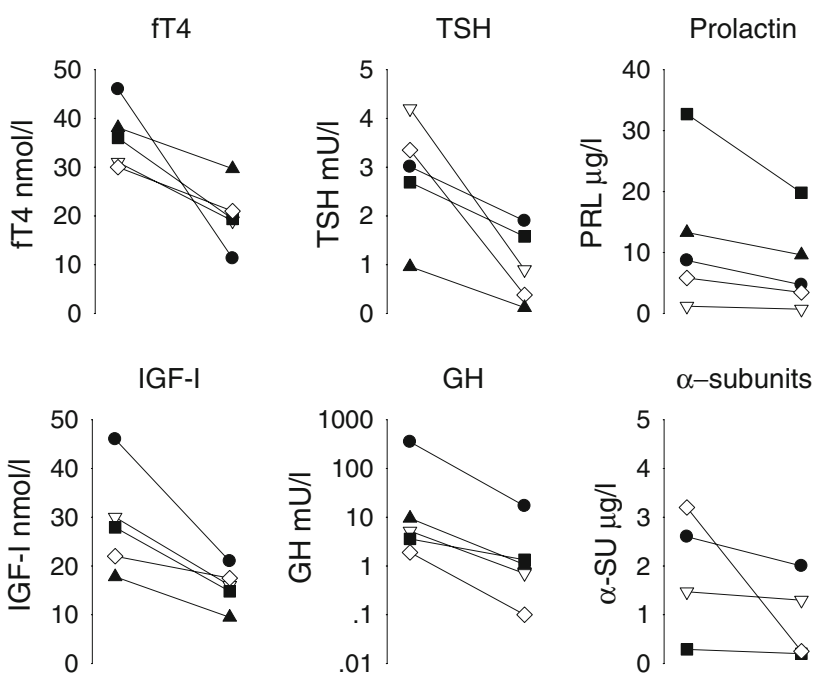

Fig. 7 Effect of octreotide treatment on fasting morning hormone concentrations in 5 patients with a thyrotropinoma. fT4 denotes serum free thyroxine. Note the logarithmic scale for GH

\section{Discussion}

This cohort of patients with a TSH-secreting pituitary adenoma maintained a high TSH pulse frequency with normal pulsing variability, increased basal and pulsatile TSH release and decreased secretory-pattern regularity. In addition, three of five patients also showed increased GH secretion, although clinically manifest in only one. Sustained increased PRL levels were present in one patient.

Previous investigations have demonstrated that frequent hormone pulses constitute feature of all endocrine adenomas, including somatotropinomas, prolactinomas, corticotropinomas and also hormone-secreting adrenal adenomas [8-10, 17]. This common finding among diverse tumors suggests that the cause of increased pulsatility is not primarily mediated via signaling of increased frequency of stimulatory peptides or neurotransmitters, but rather is an intrinsic feature of the adenoma per se.

Stability of the Weibull gamma parameter indicated that the increased TSH pulse frequency in patients is not associated with altered variability in length of interpulse intervals. Conversely, the elevated Weibull lambda parameter confirms increased TSH pulsing. The other remarkable finding was the decreased regularity of TSH secretory patterns as revealed by the increased ApEn. Approximate entropy has been investigated in a variety of altered feed-forward and feed-back states in healthy individuals, for instance in the somatotropic axis in healthy subjects during GHRH or GHRP-2 infusions and pegvisomant administration [23-25]. Increased stimulation of somatotropes is accompanied by decreased regularity (increased ApEn), and decreased IGF-I feedback by blocking the $\mathrm{GH}$ signal with the GH-receptor blocking 
drug, pegvisomant, is also associated with decreased orderliness of GH secretion. Such studies indicate that higher ApEn reflects elevated feed-forward and reduced feed-back signaling of the studied system [15, 25]. For TSH comparable conditions of diminished feedback would be primary hypothyroidism and thyroid hormone resistance, which have not been studied. In contrast, endocrine tumors are generally not well regulated by exogenous stimuli (with the possible exceptions of some GHRHsecreting carcinoid tumors and ectopic CRH-producing tumors), although diminished feedback may be present, as observed in corticotropinomas (glucocorticoids), somatotropinoma (IGF-I) and parathyroid adenomas (calcium). Thus, increased TSH ApEn in thyrotropinomas likely reflects disorganized secretion from the tumor per se. Aberrant alternative splicing of thyroid hormone-receptor $\beta 2$ mRNA encoding a thyroid hormone receptor variant lacking $\mathrm{T}_{3}$ binding activity might in principle also contribute to irregular secretion [26, 27].

Co-secretion of $\mathrm{GH}$ and prolactin is found in about onethird of patients with a thyrotropinoma [7]. Up to $16 \%$ of patients co-secrete $\mathrm{GH}$ and $11 \%$ prolactin, while cosecretion of gonadotropins is rare (about 1\%). Immunohistochemical studies report an even larger incidence of co-expression of $\mathrm{GH}$ and PRL mRNA in the thyrotrope tumors, suggesting that either these hormones are not secreted in quantities leading to clinical disease and furthermore that the tumor cell is derived from a common precursor cell [28-31].

Although all patients with a TSH-secreting adenoma secrete relatively excessive amounts of thyroid hormones, the TSH concentration in patients varies from normal to grossly elevated, in contrast with other hormone-secreting pituitary adenomas, e.g. somatotropinomas and corticotropinomas. This observation has been explained by increased biological activity of less acidic post-glycosylation isoforms of TSH [32]. Some preservation of feedback at the pituitary level cannot be ruled out, although it has not been studied in detail. Indeed, in our case series only two patients had an increased mean TSH concentration (Fig. 2), although the other patients should have had suppressed TSH levels due to elevated $\mathrm{T}_{4}\left(\mathrm{~T}_{3}\right)$ concentrations. Terminal sialylation of TSH can reduce its metabolic clearance, and indeed we found a $25 \%$ increase of the second component of the TSH half-life in our patients.

The other major cause of central hyperthyroidism is thyroid hormone resistance. This syndrome is not associated with a pituitary tumor [33]. The TRH test in this condition is normal or hyperresponsive in contrast to the blunted TSH response in thyrotropinomas. In addition, patients with this disorder do not respond to somatostatin analog therapy [34]. The results of the TRH and octreotide tests are relevant and important in this context, because we have no histological proof for a thyrotropinoma in 4 of the 6 patients, although the presence of a (micro) adenoma would not favor a resistance syndrome. Other indirect methods to discriminate between thyroid hormone resistance and thyrotropinomas are the dissociated effects of TRH on TSH and $\alpha$-subunits and the molar ratio of $\alpha$-subunits and TSH. Taking into account that one of the patients was postmenopausal (although she had a normal $\alpha$-subunit level) only two of our patients had an increased ratio. However, recent data suggest that high levels of $\alpha$-subunit and an increased ratio are not invariably present and are actually normal in $20 \%$ of patients with a thyrotropinoma [1].

Treatment modalities of thyrotropinomas include transsphenoidal surgery and/or (primary) medical treatment. Generally, surgery may cure up to 50-80\% and therapy with long-acting somatostatin analogues may be effective in about $80 \%$ of patients [35-41]. In line with the literature fasting hormone levels (TSH, fT4, GH, IGF-I and prolactin) decreased in all patients (except for $\mathrm{T}_{4}$ in the patient with a toxic nodular goiter) during treatment with octreotide-LAR, thus demonstrating that the suppressive effect was not restricted to TSH secretion. Rare subjects have had both primary hyperthyroidism and central hyperthyroidism [36, 42]. Indeed, medical therapy failure aimed at TSH normalization may lead to the correct (additional) diagnosis.

A limitation of the study is the small number of investigated patients with this rare disorder. In addition, we could only evaluate patients with TSH concentrations mostly within the normal range. Therefore, the present conclusions cannot be extrapolated to patients with much higher TSH levels.

All our patients had a significant diurnal TSH rhythm with a mean phase delay of $2.7 \mathrm{~h}$ with unchanged amplitude. Few TSH serum profiles of patients with TSH-secreting adenomas have been published, but not of co-secreted $\mathrm{GH}$ and prolactin. Samuels et al. described a female patient with a TSH-secreting tumor, who had pulsatile TSH secretion, but no diurnal rhythm when monitored by 15-min sampling for 24-h [43]. Later, the same group reported absent diurnal variation of TSH in two other thyrotropinoma patients [44]. In another report two male patients were sampled at 2-h intervals: one patient showed a clear diurnal rhythm with a significant phase delay, as observed here, whereas the other patient had no clear rhythm [45]. Finally, a male patient was described with no apparent TSH rhythm, but the rhythm was restored during treatment with bromocriptine and octreotide. Paradoxically, the mean 24-h TSH concentration increased during medical treatment [46].

This limited patient series also demonstrates abnormalities in $\mathrm{GH}$ and prolactin secretion. One patient had overt acromegaly, and two others exhibited a definitely abnormal GH secretion pattern (Fig. 5), which resembled the TSH pattern. In addition, the results of the deconvolution 
analysis also revealed (moderately in two) increased GH secretion in 3 patients, consistent with a high incidence of GH excess. Indeed, IGF-I concentrations and the SD scores were elevated in these patients, but clinical symptoms were not apparent in two individuals. Other indirect biochemical clues of hormone cosecretion were significant cross-correlations between TSH and GH (3 out of 5 patients), and between TSH and prolactin ( 5 out of 5 patients) and the phase delay of TSH and PRL diurnal rhythms. Somewhat unexpectedly, a significant correlation between TSH and $\alpha$ subunit was found in only two patients, one of whom had clinically severe acromegaly. The lack of correlation between TSH and $\alpha$-subunit suggests that their secretion is not coordinately regulated in the thyrotrope or that some tumors may consist of a mixed population of thyrotropes and purely $\alpha$-subunit-secreting cells [47].

Recent histological studies of the pituitary gland have revealed that growth hormone-secreting cells form a largescale network. This functional three-dimensional GH-network consists of cells linked with focal adherent junctions, shows robustness across the lifespan despite reversible plasticity of the architecture, for instance at puberty when GH secretion is amplified [48]. Such a network can produce rapid and synchronized hormone pulses in response to physiological needs. If a similar network exists for thyrotropes, disruptions of functional organization in TSH adenomas could explain disorganized TSH secretion, as here observed with increased ApEn in concert with the increased burst frequency. In addition, folliculo-stellate cells might be involved coordinating hormone secretion in the three-dimensional network [49]. These cells participate in scavenger activity, paracrine regulation of endocrine cells, as a source of stem cells and large-scale intercellular communication by means of long cytoplasmatic processes and gap junctions that mediate intercellular $\mathrm{Ca}^{2+}$ waves [49-53]. Observed loss of folliculostellate cells might thus contribute to abnormal hormone secretion patterns by pituitary adenomas.

In summary, TSH secretion by thyrotropinomas is characterized by increased pulse frequency with normal interpulse variability, decreased secretory regularity, enhanced hormone release and a delayed phase of the diurnal rhythm. In addition, GH and prolactin secretion also exhibit various abnormalities, ranging from decreased regularity to overt hypersecretion. We hypothesize that aberrant secretory characteristics are caused by histological and cellular alterations of the network of thyrotrophic tumor cells.

Open Access This article is distributed under the terms of the Creative Commons Attribution Noncommercial License which permits any noncommercial use, distribution, and reproduction in any medium, provided the original author(s) and source are credited.

\section{References}

1. Mariotti S (2006) Normal physiology of the hypothalamo-pituitary-thyroidal system and relation to the neural system and other endocrine gland. Chapter 4 in Thyroid Disease Manager. www.thyroidmanager.com

2. Adriaanse R, Brabant G, Prank K, Endert E, Wiersinga WM (1992) Circadian changes in pulsatile TSH release in primary hypothyroidism. Clin Endocrinol (Oxf) 37:504-510. doi: 10.1111/j.1365-2265.1992.tb01481.x

3. Faber J, Kirkegaard C, Rasmussen B, Westh H, Busch-Sorensen M, Jensen JW (1987) Pituitary-thyroid axis in critical illness. J Clin Endocrinol Metab 65:315

4. Van den Berghe G, De Zegher F, Veldhuis JD, Wouters P et al (1997) Thyrotrophin and prolactin release in prolonged critical illness: dynamics of spontaneous secretion and effects of growth hormone-secretagogues. Clin Endocrinol (Oxf) 47:599. doi: 10.1046/j.1365-2265.1997.3371118.x

5. Romijn JA, Adriaanse R, Brabant G, Prank K, Endert E, Wiersinga WM (1999) Pulsatile secretion of thyrotropin during fasting: a decrease of thyrotropin pulse amplitude. J Clin Endocrinol Metab 70:1631-1636

6. Kok P, Roelfsema F, Frolich M, Meinders AE, Pijl H (2005) Spontaneous diurnal TSH secretion is enhanced in proportion to circulating leptin in obese premenopausal women. J Clin Endocrinol Metab 90:6185-6191. doi:10.1210/jc.2005-0003

7. Beck-Peccoz P, Brucker-Davis F, Persani L, Smallridge RC, Weintraub BD (1996) Thyrotropin-secreting pituitary tumors. Endocr Rev 17:610-638. doi:10.1210/er.17.6.610

8. Van Aken MO, Pereira AM, van den Berg G, Romijn JA, Veldhuis JD, Roelfsema F (2004) Profound amplification of secretory-burst mass and anomalous regularity of ACTH secretory process in patients with Nelson's syndrome compared with Cushing's disease. Clin Endocrinol (Oxf) 60:765-772. doi: 10.1111/j.1365-2265.2004.02052.x

9. Groote Veldman R, van den Berg G, Pincus SM, Frolich M, Veldhuis JD, Roelfsema F (1999) Increased episodic release and disorderliness of prolactin secretion in both micro- and macroprolactinomas. Eur J Endocrinol 140:192-200. doi:10.1530/ eje.0.1400192

10. van den Berg G, Frolich M, Veldhuis JD, Roelfsema F (1994) Growth hormone secretion in recently operated acromegalic patients. J Clin Endocrinol Metab 79:1706-1715. doi:10.1210/ jc.79.6.1706

11. Keenan DM, Roelfsema F, Biermasz N, Veldhuis JD (2003) Physiological control of pituitary hormone secretory-burst mass, frequency and waveform: a statistical formulation and analysis. Am J Physiol Regul Integr Comp Physiol 285: R664-R673

12. Akaike H (1974) A new look at the statistical model identification. IEEE Trans Automat Contr AC-19:716-723. doi:10.1109/ TAC.1974.1100705

13. Pincus SM (2000) Irregularity and asynchrony in biologic network signals. Methods Enzymol 321:149-182. doi:10.1016/S007 6-6879(00)21192-0

14. Hartman ML, Pincus SM, Johnson ML, Matthews DH, Faunt LM, Vance ML, Thorner MO, Veldhuis JD (1994) Enhanced basal and disorderly growth hormone secretion distinguish acromegalic from normal pulsatile growth hormone release. J Clin Invest 94:1277-1288. doi:10.1172/JCI117446

15. Veldhuis JD, Straume M, Iranmanesh A, Mulligan T, Jaffe C, Barkan A, Johnson ML, Pincus S (2001) Secretory process regularity monitors neuroendocrine feedback and feedforward signaling strength in humans. Am J Physiol Regul Integr Comp Physiol 280:R721-R729 
16. Pincus SM, Hartman ML, Roelfsema F, Thorner MO, Veldhuis JD (1999) Hormone pulsatility discrimination via coarse and short time sampling. Am J Physiol 277:E948-E957

17. Van Aken MO, Pereira AM, van Thiel SW, van den Berg G, Frolich M, Veldhuis JD, Romijn JA, Roelfsema F (2005) Irregular and frequent cortisol secretory episodes with preserved diurnal rhythmicity in primary adrenal Cushing's syndrome. J Clin Endocrinol Metab 90:1570-1577. doi:10.1210/jc.2004-1281

18. Liu PY, Pincus SM, Keenan DM, Roelfsema F, Veldhuis JD (2005) Analysis of bidirectional pattern synchrony of concentration-secretion pairs: implementation in the human testicular and adrenal axes. Am J Physiol Regul Integr Comp Physiol 288:R440-R446. doi:10.1152/ajpregu.00414.2004

19. Liu PY, Pincus SM, Keenan DM, Roelfsema F, Veldhuis JD (2005) Joint synchrony of reciprocal hormonal signaling in human paradigms of both ACTH excess and cortisol depletion. Am J Physiol Endocrinol Metab 289:E160-E165. doi:10.1152/ ajpendo.00007.2005

20. Keenan DM, Veldhuis JD (2001) Hypothesis testing of the aging male gonadal axis via a biomathematical construct. Am J Physiol 280:R1755-R1771

21. Pincus SM, Mulligan T, Iranmanesh A, Gheorghiu S, Godschalk M, Veldhuis JD (1996) Older males secrete luteinizing hormone and testosterone more irregularly, and jointly more asynchronously, than younger males. Proc Natl Acad Sci USA 93:1410014105. doi:10.1073/pnas.93.24.14100

22. Veldhuis JD, Iranmanesh A, Johnson ML, Lizarralde G (1990) Twenty-four hour rhythms in plasma concentrations of adenohypophyseal hormones are generated by distinct amplitude and/or frequency modulation of underlying pituitary secretory bursts. J Clin Endocrinol Metab 71:1616-1623

23. Evans WS, Anderson SM, Hull LT, Azimi PP, Bowers CY, Veldhuis JD (2001) Continuous 24-hour intravenous infusion of recombinant human growth hormone $(\mathrm{GH})$-releasing hormone(1-44)-amide augments pulsatile, entropic, and daily rhythmic GH secretion in postmenopausal women equally in the estrogenwithdrawn and estrogen-supplemented states. J Clin Endocrinol Metab 86:700-712. doi:10.1210/jc.86.2.700

24. Bowers CY, Granda R, Mohan S, Kuipers J, Baylink D, Veldhuis JD (2004) Sustained elevation of pulsatile growth hormone (GH) secretion and insulin-like growth factor I (IGF-I), IGF-binding protein-3 (IGFBP-3), and IGFBP-5 concentrations during 30-day continuous subcutaneous infusion of GH-releasing peptide- 2 in older men and women. J Clin Endocrinol Metab 89:2290-2300. doi:10.1210/jc.2003-031799

25. Veldhuis JD, Bidlingmaier M, Anderson SM, Wu Z, Strasburger CJ (2001) Lowering total plasma insulin-like growth factor I concentrations by way of a novel, potent, and selective growth hormone (GH) receptor antagonist, pegvisomant (B2036-Peg), augments the amplitude of GH secretory bursts and elevates basal/nonpulsatile GH release in healthy women and men. J Clin Endocrinol Metab 86:3304-3310. doi:10.1210/jc.86.7.3304

26. Ando S, Sarlis NJ, Krishnan J, Feng X, Refetoff S, Zhang MQ, Oldfield EH, Yen PM (2001) Aberrant alternative splicing of thyroid hormone receptor in a TSH-secreting pituitary tumor is a mechanism for hormone resistance. Mol Endocrinol 15:15291538. doi:10.1210/me.15.9.1529

27. Ando S, Sarlis NJ, Oldfield EH, Yen PM (2001) Somatic mutation of TR beta can cause a defect in negative regulation of TSH in a TSH-secreting pituitary tumor. J Clin Endocrinol Metab 86:5572-5576. doi:10.1210/jc.86.11.5572

28. Sanno N, Teramato A, Matsuno A, Takekoshi S, Osamura RY (1995) GH and PRL gene expression by nonradioisotopic in situ hybridization in TSH-secreting pituitary adenomas. J Clin Endocrinol Metab 80:2518-2522. doi:10.1210/jc.80.8.2518
29. Teramoto A, Sanno N, Tahara S, Osamura YR (2004) Pathological study of thyrotropin-secreting pituitary adenoma: plurihormonality and medical treatment. Acta Neuropathol 108:147-153. doi:10.1007/s00401-004-0863-x

30. Gittoes NJ, McCabe CJ, Verhaeg J, Sheppard MC, Franklyn JA (1998) An abnormality of thyroid hormone receptor expression may explain abnormal thyrotropin hormone production in thyrotropin-secreting pituitary tumors. Thyroid 8:9-14

31. Clarke MJ, Erickson D, Castro MR, Atkinson JL (2008) Thyroidstimulating hormone pituitary adenomas. J Neurosurg 109:17-22. doi:10.3171/JNS/2008/109/7/0017

32. Beck-Peccoz P, Persani L (1994) Variable biological activity of thyroid-stimulating hormone. Eur J Endocrinol 131:331-340

33. Weiss RE, Refetoff S (2000) Resistance to thyroid hormone. Rev Endocr Metab Disord 1:97-108. doi:10.1023/A:1010072605757

34. Mannavola D, Persani L, Vannuchi G, Zanardelli M, Fugazzola L, Verga U, Facchetti M, Beck-Peccoz P (2005) Different responses to chronic somatostatin analogues in patients with central hyperthyroidism. Clin Endocrinol (Oxf) 62:176-181. doi: 10.1111/j.1365-2265.2004.02192.x

35. Brucker-Davis F, Oldfield EH, Skarulis MC, Doppman JL, Weintraub BD (1999) Thyrotropin-secreting pituitary tumors: Diagnostic criteria, thyroid hormone sensitivity, and treatment outcome in 25 patients followed at the National Institutes of Health. J Clin Endocrinol Metab 84:476-486

36. Sanno N, Teramoto A, Yoshiyuki Osamura R (2001) Thyrotropin-secreting pituitary adenomas. Clinical and biological heterogeneity and current treatment. J Neurooncol 54:179-186. doi:10.1023/A:1012917701756

37. Valdes Socin H, Chanson P, Delemer B, Tabarin A, Rohmer V, Mockel J, Stevenaert A, Beckers A (2003) The changing spectrum of TSH-secreting pituitary adenomas: diagnosis and management in 43 patients. Eur J Endocrinol 148:433-442. doi: 10.1530/eje.0.1480433

38. Chanson P, Weintraub BD, Harris AG (1993) Octreotide therapy for thyroid-stimulating hormone-secreting pituitary adenomas: a follow-up of 52 patients. Ann Intern Med 119:236-240

39. Kuhn JM, Arlot S, Levebre H, Caron P, Cortet-Rudelli C, Archambaud F, Chanson P, Tabarin A, Goth MI, Blumberg J, Catus F, Ispas S, Beck-Peccoz P (2000) Evaluation of the treatment of thyrotropin-secreting pituitary adenomas with a slow release formulation of the somatostatin analog Lanreotide. J Clin Endocrinol Metab 85:1487-1491. doi:10.1210/jc.85.4. 1487

40. Caron P, Arlot S, Bauters C, Chanson P, Kuhn JM, Pugeat M, Marechaud R, Teutsch C, Vidal E, Sassano P (2001) Efficacy of the long-acting octreotide formulation (Octreotide-Lar) in patients with thyrotropin-secreting pituitary adenomas. J Clin Endocrinol Metab 85:1487-1491

41. Kienitz T, Quinkler M, Strasburger CJ, Ventz M (2007) Longterm management in five cases of TSH-secreting pituitary adenomas: a single center study and review of the literature. Eur J Endocrinol 157:39-46. doi:10.1530/EJE-07-0098

42. Abs R, Stevenaert A, Beckers A (1994) Autonomously functioning thyroid nodules in a patient with a thyrotropin-secreting pituitary adenoma: possible cause-effect relationship. Eur $\mathrm{J}$ Endocrinol 131:355-358

43. Samuels MH, Wood WM, Gordon DF, Kleinschmidt-DeMasters BK, Lillehei K, Ridgway EC (1989) Clinical and molecular studies of a thyrotropin-secreting pituitary adenoma. J Clin Endocrinol Metab 68:1211-1215

44. Samuels MH, Henry P, Kleinschmidt-Demasters BK, Lillehei K, Ridgway EC (1991) Pulsatile glycoprotein hormone secretion in glycoprotein-producing pituitary tumors. J Clin Endocrinol Metab 73:1281-1288 
45. Beckers A, Abs R, Mahler C, Vandalem JL, Pirens G, Hennen G, Stevenaert A (1991) Thyrotropin-secreting pituitary adenomas: report of seven cases. J Clin Endocrinol Metab 72:477-483

46. Adriaanse R, Brabant G, Endert E, Bemelman FJ, Wiersinga WM (1994) Pulsatile thyrotropin and prolactin secretion in a patient with a mixed thyrotropin- and prolactin-secreting pituitary adenoma. Eur J Endocrinol 130:113-120

47. Terzolo M, Orlandi F, Bassetti M, Medri G, Paccotti P, Cortelazzi D, Angeli A, Beck-Peccoz P (1991) Hyperthyroidism due to a pituitary adenoma composed of two different cell types, one secreting alpha-subunit alone and another one cosecreting alphasubunit and thyrotropin. J Clin Endocrinol Metab 72:415-421

48. Bonnefont X, Lacampagne A, Sanchez-Hormigo A, Fino E, Creff A, Mathieu MN, Smallwood S, Carmignac D, Fontanaud P, Travo P, Alonso G, Courtois-Coutry N, Pincus SM, Robinson IC, Mollard P (2005) Revealing the large-scale network organization of growth hormone-secreting cells. Proc Natl Acad Sci USA 102:16880-16885. doi:10.1073/pnas.0508202102
49. Denef C (2008) Paracrinicity: the story of 30 years of cellular pituitary crosstalk. J Neuroendocrinol 20:1-70. doi:10.1111/ j.1365-2826.2008.01676.x

50. Devnath S, Inoue K (2008) An insight to pituitary folliculostellate cells. J Neuroendocrinol 20:687-691. doi:10.1111/j.13652826.2008.01716.x

51. Horvath E, Kovacs K (2002) Folliculo-stellate cells of the human pituitary: a type of adult stem cell? Ultrastruct Pathol 26:219228. doi:10.1080/01913120290104476

52. Sato G, Shirasawa N, Sakuma E, Sato Y, Asai Y, Wada I, Horiuchi O, Sakamoto A, Herbert DC, Soji T (2005) Intercellular communications within the rat anterior pituitary XI: an immunohistochemical study of distributions of S-100 positive cells in the anterior pituitary of the rat. Tissue Cell 37:269-280. doi: 10.1016/j.tice.2005.03.004

53. Tachibana O, Yamashima $\mathrm{T}$ (1988) Immunohistochemical study of folliculo-stellate cells in human pituitary adenomas. Acta Neuropathol 76:458-464. doi:10.1007/BF00686384 